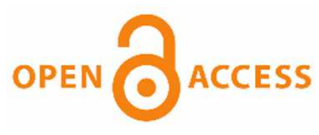

\title{
The Effective Factors on Knowledge Management in Universities from Physical Education Instructors' Viewpoints
}

Authors' contribution:

A) conception and design of the study

B) acquisition of data

C) analysis and interpretation of data

D) manuscript preparation

E) obtaining funding

\author{
Shahram Shafiee ${ }^{\mathrm{A}, \mathrm{D}, \mathrm{E}}$, Mojtaba Eskandaripour ${ }^{\mathrm{A}-\mathrm{C}}$, Samira
}

Soltani ${ }^{\mathrm{D}-\mathrm{E}}$

University of Guilan, Rasht, Iran

ABSTRACT

The aim of the present study was to investigate the relation of technology, organizational culture and emotional intelligence with knowledge management using the mediators of organizational structure and empowerment. The methodology of the research was descriptive-correlational and the population of the study consisted of all the physical education instructors of Zanjan universities with three-year teaching record (61 people). The population size using the census sample criterion. Research tool included Stankosky and Baldanza's technology, organizational culture and structure, Bar-On's emotional intelligence inventory, Spreitzer and Mishra's empowerment, Kordnaij et al. and Newman and Conrad's knowledge management framework questionnaires. The structural equation modelling was used via Smart PLS 2 software for analyzing the data. The results showed that there is a negative and significant relation between technology and knowledge management. Also, there is significant relation between organizational culture and knowledge management, emotional intelligence and knowledge management, technology and organizational structure, organizational culture and organizational structure, technology and empowerment, organizational culture and empowerment, organizational structure and empowerment and empowerment and knowledge management; while the significance of relations between organizational structure and knowledge management and emotional intelligence and empowerment were not confirmed. The results of the present study can help the people in charge of education and research in the universities in order to produce, keep and use the needed knowledge related to proper time and place by making decisions and educating people.

KEYWORDS technology, organizational culture, knowledge management, emotional intelligence

\section{Introduction}

Today's organizations are under severe internal and external pressures. Meanwhile, the thing which distinguishes the organizations from one another, is the organizational knowledge or what we call "intangible assets". The knowledge of an organization needs management in order to increase the efficiency and effectiveness; and that is where a concept called "knowledge management" comes into being (Damghanian et al., 2013). The knowledge management refers to the systematic and consistent process of coordinating the vast organizational activities such as the acquisition, creation, maintenance, sharing and using the knowledge by the 
individuals and groups in order to realize the organizational goals (Ashna et al., 2013). In the present study, the general knowledge management model proposed by Newman and Conrad is used to investigate the knowledge management variable, which consists of items such as knowledge creation, maintenance, knowledge transfer and knowledge application.

The knowledge management has two main approaches; the first one is based on the knowledge management technology which involves a wide range of approaches, systems and operational methods that are designed to support and administer the knowledge-based processes. According to such attitude, the knowledge management process is mainly based on the information technology (Niaz-Azari \& Amuee, 2007).

However, one should note that information technology is only one sector of knowledge management and gaining success in this area, requires that various organizational factors available in an organization, such as technology, organizational culture, human resources and organizational structure, possess certain features and have the adequate coordination and integrity (Abdolali, 2010).

The second approach is the social approach. The focus of this approach is on members of the organizations, as it is believed that knowledge is a social phenomenon. The scholars of the field have identified various factors as the ones which influence the knowledge management establishment, regarding the two mentioned approaches. Another effective factor that the experts have maintained, is the organizational culture. The proper culture for knowledge management is the one in which creativity and innovation are considered as values; the employees are allowed to experience and learn through trial and error; the atmosphere of the organization is so good that all the staff are willing to learn and transfer their experiences and knowledge to others; and in such a proper culture, the individuals are assessed and encouraged according to their share in the knowledge development in the organization. Such a culture can bring about the fair knowledge transfer in the organization (Niaz-Azari \& Amuee, 2007).

In many scientific articles, this idea is emphasized that knowledge should be established in individuals' minds not in the organizational files, but often this personal aspect of the knowledge management is ignored (HosseiniSadr \& Abasaltian, 2013). The human knowledge of a person is mainly located in his/her brain, which is also referred as his/her memory or the knowledge's physical location. However, knowledge is an intangible thing which cannot be fully identified and it is not considered as a physical material and here, the psychological features, the emotional intelligence, the motivation and the human will, are so significant (Zavareghi, 2009). The emotional intelligence which is introduced as a kind of intelligence involves of an accurate understanding of one's emotions and also the accurate interpretation of others' emotional statuses. The emotional intelligence, evaluates the individual in case of emotions, that is, it assesses the extent that the individual is aware of his/her emotions and feelings and how he can control and manage those impulses. The remarkable point in case of emotional intelligence is that the emotional intelligence capacities are not inborn and they can be learned (Nazem \& Lajevardi, 2011).

However, most managers can hardly understand the practical aspects of knowledge management. Furthermore, the management paradigm has been evolved and changed in several certain periods. One of the main factors underlying such changes, is the organizational structure. The organizational structure is the main force for such change, as it is regarded as the foundation and framework for all organizational decisions and processes (Rahmanseresht et al., 2011).

Another factor in knowledge management establishment is the human force. The committed human force possessing unique capacities such as mastering the advanced technologies, being able to make correct decisions and judgements, self-control, and self-direction, is considered as a determining factor in establishing the knowledge management (Niaz-Azari \& Amuee, 2007). Developing the empowerment techniques and knowledge management, is a step forward in enhancing the staff's awareness and efficiency of organizations. Empowering the staff is one of the effective techniques in promoting the experts' efficiency and the optimal use of their capacities and abilities regarding the organizational objectives (Rastadmehr et al., 2014). 
Hence, factors such as technology, organizational culture, emotional intelligence, organizational structure and staff empowerment are effective in knowledge management.

Many studies have been conducted on infrastructures of knowledge management and many factors have been introduced in those studies (Niaz-Azari \& Amuee, 2007; Hassanzadeh, 2009; Abdi, 2010; Jafari et al., 2011; Bhatt, 2001; Zheng et al., 2010). The use of information technology in knowledge management leads to the increased level of access to knowledge and more rapid knowledge transfer to other members of the organization (Niaz-Azari \& Amuee, 2007). In today's science, the most rapidly changing factor is the technology (Jeibing et al., 2013). In the previous studies on the relation between technology and knowledge management, the results confirm a significant relation between the mentioned variables (Jokar, 2010; Azizi et al., 2010; Sobhani et al, 2013; Tseng, 2008; Neels \& Johnson, 2010; Meyer \& Marion, 2013). Also, studying the direct and indirect relations among the variables has indicated a positive and significant relation (Damghanian, 2013).

The importance of organizational culture has been confirmed in knowledge management, in many studies and the scholars of the filed regard the organizational culture as one of the necessities of knowledge management (Alvani et al., 2007). In addition, the improper organizational culture is considered as one of the latent factors underlying the failure of knowledge management projects, as having a good organizational culture is necessary for the success of knowledge management in organizations (Pillania, 2006). Various studies have investigated the relation between organizational culture and knowledge management and the existence of a significant relation between those two is confirmed (Gholtash et al., 2011; Ashna et al, 2013; Balthazard \& Cooke, 2004; Allameh et al., 2011; Mueller, 2014).

The studies show that those managers are successful that can have effective relationship with their human resources. In this regard, the emotional intelligence is one of the items that can play a great role in the relations between managers and the organization members, and it is considered as an inevitable condition in the organization. Recently, some scholars have found that the emotional intelligence is more important than the intelligence quotient for the staff (Mohammadi, 2013). The findings on the relation of emotional intelligence and knowledge management shows a significant relation (Hosseini-Sadr \& Abasaltian; Mohseninia, 2013; Mohammadi, 2013; Safaju, 2015). However, some have reported lack of significant relation and poor correlation between these variables, as well (Nazem \& Lajevardi, 2011).

Furthermore, using information technology can bring about change in the organization's structure (Baghban et al., 2012). The relation between technology and the organizational structure dimension has been investigated in some studies and the results show that there is a significant relation between these two variables (Mostafaee, 2009; Azizi et al., 2013; Noruzi \& Navvabi, 2014; Dibrell \& Miller, 2002; Chatzoglou et al., 2011). The organizational culture can also influence the organizational structure, depending on its strength (SafariAboksari, 2012). The literature review of the relation between the organization culture and organizational structure dimensions also show that these variables have significant relationship with one another (Kordnaeij et al., 2009; Hariri \& Jafari, 2012; Safari-Aboksari, 2012; Ahlin \& Bergstrom, 2010). The organizational structure is also effective in the knowledge management process (Assadi, 2013). The researchers have maintained that there is significant relation between the dimensions of organizational structure and knowledge management (Naghipour et al., 2008; Karbassi-Yazdi, 2011; Monavarian et al., 2011; Chen and et al., 2010).

Nowadays, the focus is on the use of up-to-date technologies in order to enhance the staff's power. The staff empowerment means that the staff could fully understand their tasks, before the managers tells them (Savery \& Luks, 2000). In the related literature, the studies on the relation between technology and psychological /structural empowerment shows the significant relation among these variables (Kamalian et al., 2013; Ebadi, 2016; Shirazi, 2012).Also, one can bring about the proper ground for staff empowerment by creating the desired organizational culture (Hardy and Leiba-o'sullivan, 1998). In investigating the relation between the organizational culture and empowerment, some researchers have found a significant relation (TavanaeeShahroodi \& Mahram, 2010; Gholifar et al., 2011; Nassiri et al., 2012; Shaemi-Barzoki et al., 2013; Singler \& 
Pearson, 2000; Dimitriades \& Maroudas, 2007).Nowadays, the knowledge related to feelings and emotions can be used in order to improve the organizational performance (Bayat, 2013). The emotional intelligence can make the success prediction possible as it shows how a person can use his knowledge immediately (Shamshirkar, 2010). The studies on the relation between the emotional intelligence and empowerment have led to different results. However, many studies have confirmed the significant relation between the mentioned variables (Babalhavaeji \& Aghakishizadeh, 2010; Abedi et al., 2011). The organizational structure is introduced as one of the effective factors underlying the staff empowerment. The matrix organizational structure can empower the structures by permeating the hierarchy of the official administration and focusing on the customers regarding the organizational strategies (Storm \& Wallace, 2003). Also, there have been some studies with the aim of investigating the relation between dimensions of organizational structure and empowerment. The results showed a negative and significant relation between the traditional, concentrated and inactive organizational structure and the empowerment (Zabihi et al., 2013; Samadi-Miarkolaee et al., 2015; Miri et al., 2011; Vazifehdoost et al., 2012). The causal relation between the organizational structure dimensions and psychological empowerment has been also observed (Farahani et al., 2014). The point is without empowered staff who can and want to play effective role in establishing the knowledge management, one cannot guarantee any success in such processes. Consequently, the positive and significant relation between psychological empowerment and knowledge management is widely focused in studies, which has led to the high impact of empowerment on knowledge management (Rastadmehr et al., 2014; Hislop 2003; Shahnawaz, 2006; O'Neill \& Adya, 2007).

One should note that in state sector, applying knowledge management can cut the costs and promote the services. The universities and research institutes and other state or private companies face the same challenge and finding a solution can give a boost to the national development, contributing to coordinate the country's progress in case of long-term, mid-term and even short-term plans. If the knowledge management is not implemented properly, the organization would face entropy and it would become difficult to bear the fruits of such important factor, which eventually leads to the proper organizational direction on its strategic route (Saadizadeh, 2014).

Considering the fact that the universities and higher education institutes are regarded as the largest official social organizations in case of size and wide range of variety of intellectual capitals, they should be the pioneers of other organizations in establishing the knowledge management as their main capacity, and they should take the role of the leader, focusing their main activities on learning, creating, maintaining, transferring and applying the knowledge, as knowledge and educational organizations. Nowadays, the experts of the field believe that the university instructors are among the most significant classes of any society, and it is because they are regarded as the most effective factor in changing the behaviors and skills leading to empowering the students, and they are also capable of influencing the institutes, organizations, society and the learners. In this regard, one of the most important techniques for gaining the desired educational objectives and cutting the costs, is to establish knowledge management in universities and other higher education institutes.

Despite the importance of knowledge management in creating and managing the intangible assets of organizations, literature of the field is so narrow. Hence, in this study, by identifying the relations of technology, organizational culture and emotional intelligence with knowledge management, the researcher is seeking to show the significance of such variables in implementing the knowledge management and considering Figure 1, he also wants to investigate the important role of organizational structure and staff empowerment as mediators among technology, organizational culture, emotional intelligence and knowledge management. 


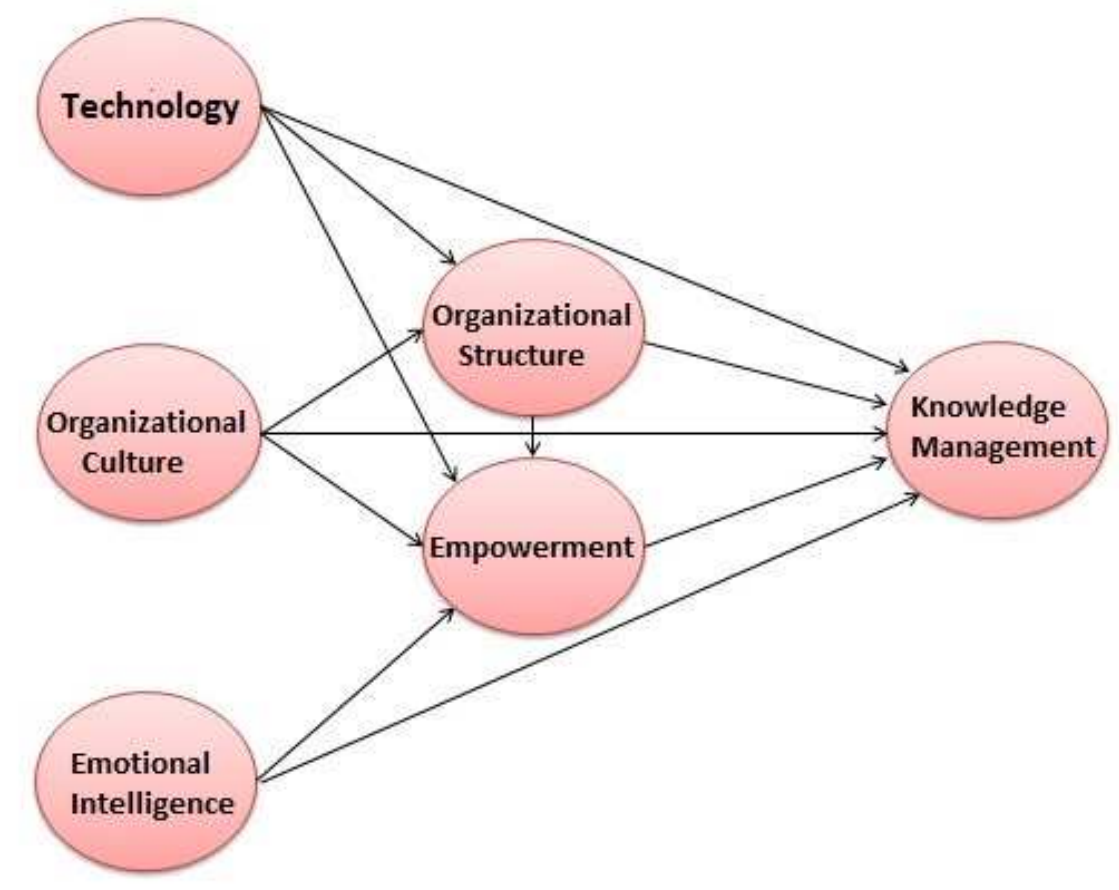

Figure 1. Conceptual model of the research

Source: own study

\section{Methods}

The present study in case of aim is of applied type, and in case of data gathering technique, it is descriptivecorrelative type. The population of the study consisted of all the instructors of physical educations in Zanjan universities (61 people) with more than three years of teaching record. The sample size was determined as a census sample equaling to the population size (61 people). The research instruments of the variables included the demographic questionnaires with 4 questions for features such as gender, age, university title and teaching record. Stankosky \& Baldanza's questionnaires (2001) with 8 questions on technology, 7 questions on organizational culture and 7 questions on organizational structure were used. Bar-On's emotional intelligence inventory (1997) consisting of 15 items, Sprietzer's psychological empowerment questionnaire (1995) and Mishra (1997) with 15 items and Kordnaeij and others' structural empowerment (1994) with 12 items were used for evaluating the empowerment. For assessing the knowledge management, the knowledge management questionnaire of Newman and Conrad (2000) with 19 items was applied. Considering the fact that these questionnaires were used in many studies and their validity were confirmed, in this study also the scholars and the experts of the field (7 people) were asked to verify the validity, and after some sessions and applying some modifications, the content validity of the questionnaires were confirmed. Considering the use of SMART PLS 2 software and structural equations modeling, among the other measurement methods used in the present study, proposed by Fornell and Larcker (1981), one can mention the convergent and discriminant validity, through them the convergent validity for variables technology, organizational culture, emotional intelligence, organizational structure, empowerment and knowledge management are reported 0.537, 0.560, 0.519, 0.539, $0.520,0.541$, respectively. The values higher than 0.5 show the acceptable convergent validity. The discriminant validity is also presented in the table. In order to determine the reliability, the index reliability which includes the Cronbach's alpha test and a better criterion called composite reliability are used. In the present study, the 
values of Cronbach's alpha and composite reliability for all the variables are higher than 0.7 which indicates the high reliability of the research instruments.

\section{Results}

The results in case of the demographic features are presented in Table 1. According to the results, it was clear that the highest frequency with 44.3 percent ( 27 people) belonged to the 33-37 age range. 36.1 percent (22 people) were female and the 63.9 percent ( 39 people) were male. Also, most of the subjects were from Islamic Azad University with 24.6 percent (15 people). The highest frequency with 18 percent (11 people) belonged to the persons with five years of teaching record.

Table 1. Frequency distribution of sample subjects based on demographic features

\begin{tabular}{|c|c|c|c|}
\hline \multicolumn{2}{|l|}{ Variable } & Percentage & $\begin{array}{l}\text { Frequency } \\
\text { (Number of } \\
\text { People) }\end{array}$ \\
\hline \multirow{4}{*}{ Age } & $33-37$ & 44.3 & 27 \\
\hline & $38-42$ & 34.5 & 21 \\
\hline & $43-47$ & 6.5 & 4 \\
\hline & $48-52$ & 9.8 & 6 \\
\hline \multirow{3}{*}{ Gander } & $53-57$ & 4.9 & 3 \\
\hline & Female & 36.1 & 22 \\
\hline & Male & 63.9 & 39 \\
\hline \multirow{8}{*}{ University } & Zanjan & 11.5 & 7 \\
\hline & Islamic Azad & 24.6 & 15 \\
\hline & Payam-e-noor & 16.4 & 10 \\
\hline & Sports\& Youth & 18.0 & 11 \\
\hline & Red Crescent & 4.9 & 3 \\
\hline & SAMA University & 6.6 & 4 \\
\hline & Rouzbeh & 6.6 & 4 \\
\hline & Farhangian & 11.5 & 7 \\
\hline \multirow{9}{*}{$\begin{array}{l}\text { Teaching } \\
\text { Record } \\
\text { (Year) }\end{array}$} & 4 & 11.5 & 7 \\
\hline & 5 & 18.0 & 11 \\
\hline & 6 & 11.5 & 7 \\
\hline & 7 & 14.8 & 9 \\
\hline & 8 & 14.8 & 9 \\
\hline & 9 & 16.4 & 10 \\
\hline & 10 & 16.4 & 4 \\
\hline & 11 & 4.9 & 3 \\
\hline & 16 & 1.6 & 1 \\
\hline
\end{tabular}

Source: own study.

In general, the analysis done by means of PLS software, consists of three parts: measurement, structural model and general model. The measurement model includes the questions (items) of each dimension accompanying that dimension, and the relations among the questions and dimensions are analyzed in this part. The structural model part consists of all the constructs proposed in the main research model and the correlation rate and the relations among the constructs are focused in this part. In the general model part, which involves both the measurement and structural model, after confirming its GOF, the GOF investigation of the model is completed. In the following pages, the assessment and GOF of each of these models are discussed. 
Table 2. GOF indexes of measurement model, structural model and general model

\begin{tabular}{lllllllll}
\hline Variables & CR & $\begin{array}{l}\text { Cronbach's } \\
\text { alpha }\end{array}$ & AVE & DR & $\mathbf{R}^{2}$ & $\mathbf{Q}^{2}$ & $\begin{array}{l}\text { Commu } \\
\text { nality }\end{array}$ & GOF \\
\hline $\begin{array}{l}\text { Technology } \\
\begin{array}{l}\text { Organizational } \\
\text { Culture }\end{array}\end{array}$ & 0.861 & 0.818 & 0.573 & 0.733 & - & - & - \\
$\begin{array}{l}\text { Emotional } \\
\text { Intelligence }\end{array}$ & 0.822 & 0.728 & 0.560 & 0.748 & - & - & - & \\
$\begin{array}{l}\text { Organizational } \\
\begin{array}{l}\text { Structure } \\
\text { Empowerment }\end{array}\end{array}$ & 0.881 & 0.853 & 0.519 & 0.720 & - & - & - & 0.676 \\
$\begin{array}{l}\text { Knowledge } \\
\text { Management }\end{array}$ & 0.920 & 0.906 & 0.520 & 0.721 & 0.910 & 0.467 & 0.520 & \\
\hline
\end{tabular}

Source: own study

Figure 2 shows the modified research model where three variables: technology, organizational culture and emotional intelligence (independent) are regarded as exogenous and three variables: organizational structure, empowerment (mediator) and knowledge management (dependent) are regarded as endogenous. In order to calculate the correlation value of indexes of a construct with that construct, the factor loadings are used whose proper values is equal or greater than 0.4 .

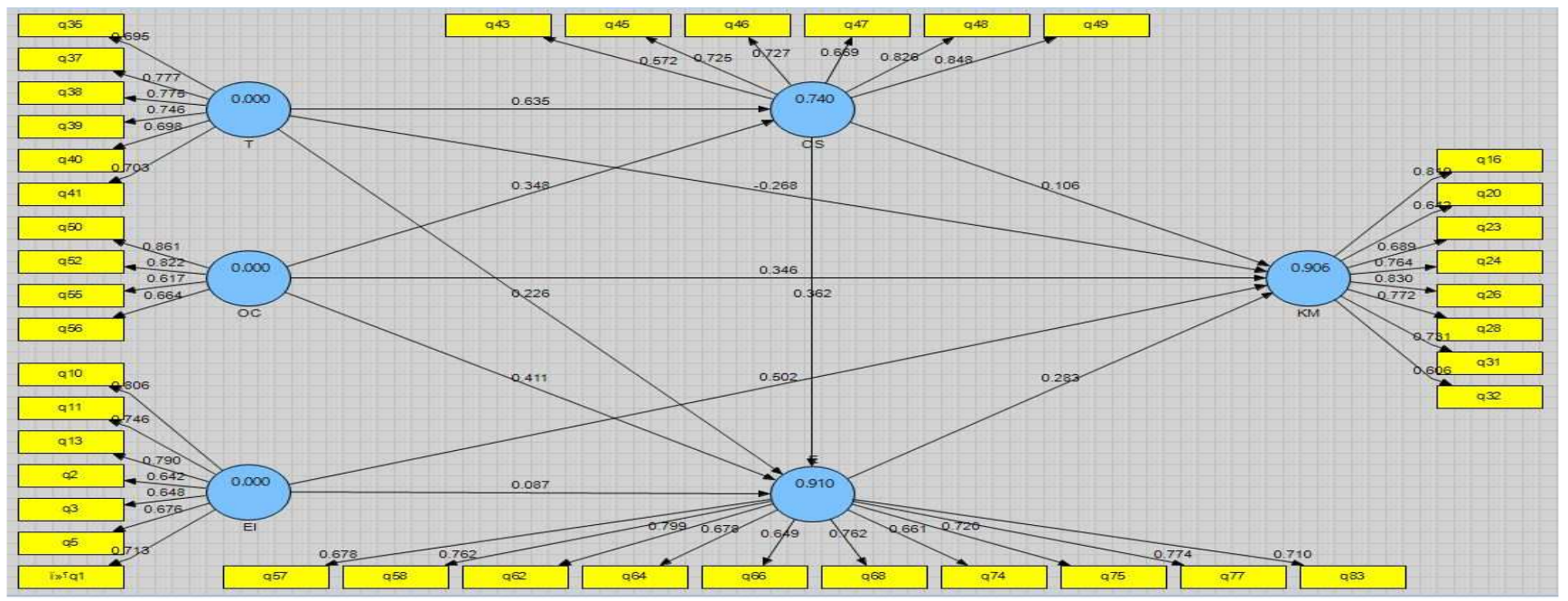

Figure 2. Standardized coefficients model of factor loadings

Source: own study

Composite Reliability and Cronbach's Alpha: in order to test the reliability these tests are used and the necessary value for reliability confirmation is getting greater than 0.7 . Table 2 shows the reliability and validity indexes for all the research variables. All these variables are greater than 0.7 which shows the reliability of the measurement instrument.

Convergent Validity: this item shows the correlation value of a construct with its indexes, where the greater the correlation value is, the higher the GOF is. The value greater than 0.5 shows the acceptable convergent validity. As it is obvious in Table 2, all the values in the constructs are greater than 0.5 , so the questions gaining convergent validity value under 0.5 , that is, 12 questions (q7, q9, q36, q42, q44, q51, q59, q60, q72, q78, q81, q82) were omitted. The following analyses are done based on the confirmed questions.

Discriminant Validity: The relation value of a construct with its indexes is calculated through comparing its relation with other constructs. Discriminant validity is acceptable in a level where the squared value of the convergent validity for each construct is higher than the common variance between that construct and the other constructs of the model. In PLS investigation, this item is studied using a matrix presented in Table 3. 
Table 3. Fornell and Larcker's matrix

Source: Fornell \& Larcker, 1981.

As it is presented in Table 3, one can roughly confirm the discriminant validity of the model at the level of the

\begin{tabular}{|c|c|c|c|c|c|c|}
\hline $\begin{array}{l}\text { Fornell and } \\
\text { Larcker's } \\
\text { Matrix }\end{array}$ & $\begin{array}{l}\text { Emotional } \\
\text { Intelligence }\end{array}$ & Empowerment & $\begin{array}{c}\text { Knowledge } \\
\text { Management }\end{array}$ & $\begin{array}{c}\text { Organizational } \\
\text { Culture }\end{array}$ & $\begin{array}{l}\text { Organization } \\
\text { al Structure }\end{array}$ & Technology \\
\hline $\begin{array}{l}\text { Emotional } \\
\text { Intelligence }\end{array}$ & 0.720 & & & & & \\
\hline Empowerment & 0.760 & 0.721 & & & & \\
\hline $\begin{array}{l}\text { Knowledge } \\
\text { Management }\end{array}$ & 0.764 & 0.783 & 0.736 & & & \\
\hline $\begin{array}{l}\text { Organizational } \\
\text { Culture }\end{array}$ & 0.716 & 0.721 & 0.778 & 0.748 & & \\
\hline $\begin{array}{l}\text { Organizational } \\
\text { Structure }\end{array}$ & 0.720 & 0.785 & 0.781 & 0.658 & 0.734 & \\
\hline Technology & 0.709 & 0.788 & 0.616 & 0.487 & 0.705 & 0.733 \\
\hline
\end{tabular}

construct which demonstrates the adequate discriminant validity and acceptable GOF of the measurement model.

T-values: The first and the foremost criterion for measuring the relation among the constructs in a model (structural) is the t-value. If this value is greater than 1.96, it confirms the relation among the constructs and consequently, the research hypotheses confirmation is at $95 \%$ confidence level. In the following lines, the tvalues of each model are presented in table 4.

Table 4. T-values t of relations of each variables with one another

\begin{tabular}{llll}
\hline Variables Relations & T-values & Variables Relations & $\begin{array}{l}\text { T- } \\
\text { values }\end{array}$ \\
\hline $\begin{array}{l}\text { Technology } \rightarrow \text { Knowledge Management } \\
\text { Organizational Culture } \rightarrow \text { Knowledge } \\
\text { Management }\end{array}$ & 2.766 & Technology $\rightarrow$ Empowerment & 2.992 \\
$\begin{array}{l}\text { Emotional Intelligence } \rightarrow \text { Knowledge } \\
\text { Management }\end{array}$ & 2.815 & Organizational Culture $\rightarrow$ Empowerment & 4.632 \\
$\begin{array}{l}\text { Technology } \rightarrow \text { Organizational Structure } \\
\begin{array}{l}\text { Organizational Culture } \rightarrow \text { Organizational } \\
\text { Structure }\end{array}\end{array}$ & 6.357 & Emotional Intelligence $\rightarrow$ Empowerment & 0.815 \\
$\begin{array}{l}\text { Organizational Structure } \rightarrow \text { Knowledge } \\
\text { Management }\end{array}$ & 3.221 & $\begin{array}{l}\text { Organizational Structure } \rightarrow \\
\text { Empowerment } \\
\text { Empowerment } \rightarrow \text { Knowledge } \\
\text { Management }\end{array}$ & 3.539 \\
\hline
\end{tabular}

Source: own study

Considering table 4, the paths where the relations among the research variables are greater than 1.96 and significant are obvious. This significance shows the correct prediction of research model relations. Also, in this model, the path among the organizational structure, knowledge management, emotional intelligence and empowerment have significance level lower than 1.96.

Coefficient of Determination $\left(\mathrm{R}^{2}\right)$ : This is a criterion used for relating the measurement and structural parts of the structural equations modeling, which shows the impact left on an exogenous variable by an endogenous one, calculated only for the endogenous constructs of the model (dependent) at three levels of weak (0.19), mild (0.33) and strong (0.67). Table 2 shows that the coefficient of determination value for variables of organizational structure, empowerment, knowledge management are 0.740, 0.910, 0.906 respectively, which are greater than 0.67. This means that the structural model of the research has strong GOF. 
$\mathrm{F}^{2}$ : determines the intensity of the relation among the model's constructs. The impact value criterion can use $\mathrm{F}^{2}$ to analyze the constructs. Values $0.02,0.15$, and 0.35 are in order the indication of weak, mild and strong impacts of a construct on another. In order to calculate the impact value, we have:

$\mathrm{F}^{2}=\frac{\mathrm{R}^{\wedge} 2 \text { included }-\mathrm{R}^{\wedge} 2 \text { excluded }}{1-\mathrm{R}^{\wedge} 2 \text { included }}$

In order to calculate the impact factor of the technology construct on organizational structure construct, first $\mathrm{R}^{2}$ value was determined after omitting the technology construct from the structural model which equaled to 0.657. Then, after putting the values in the formula, we will have:

$\mathrm{F}^{2}=\frac{\mathrm{R}^{\wedge} 2 \text { included }-\mathrm{R}^{\wedge} 2 \text { excluded }}{1-\mathrm{R}^{\wedge} 2 \text { included }}=\frac{0 / 740-0 / 657}{1-0 / 740}=0 / 319$

Hence, $\mathrm{F}^{2}$ of the technology construct on organizational structure construct equals 0.319 which shows the high impact of the technology construct on organizational structure construct.

For the three other relations, we will act as following:

$\mathrm{F}^{2}=\frac{\mathrm{R}^{\wedge} 2 \text { included }-\mathrm{R}^{\wedge} 2 \text { excluded }}{1-\mathrm{R}^{\wedge} 2 \text { included }}=\frac{0 / 740-0 / 650}{1-0 / 740}=0 / 346$

$\mathrm{F}^{2}$ of the organizational culture construct on organizational structure construct equals 0.346 which shows the high impact of the organizational culture construct on organizational structure construct.

$\mathrm{F}^{2}=\frac{\mathrm{R}^{\wedge} 2 \text { included }-\mathrm{R}^{\wedge} 2 \text { excluded }}{1-\mathrm{R}^{\wedge} 2 \text { included }}=\frac{0 / 910-0 / 899}{1-0 / 910}=0 / 120$

$\mathrm{F}^{2}$ of the technology construct on empowerment construct equals 0.120 which shows the mild impact of the organizational culture construct on organizational structure construct.

$\mathrm{F}^{2}=\frac{\mathrm{R}^{\wedge} 2 \text { included }-\mathrm{R}^{\wedge} 2 \text { excluded }}{1-\mathrm{R}^{\wedge} 2 \text { included }}=\frac{0 / 910-0 / 857}{1-0 / 910}=0 / 589$

$\mathrm{F}^{2}$ of the organizational culture construct on empowerment construct equals 0.589 which shows the high impact of the organizational culture construct on organizational structure construct.

Predictive Power Criterion: Models with acceptable GOF in structural part, should have the capacity to predict the indexes related to the endogenous constructs of the model. If the prediction power in case of an endogenous construct, gets three values of $0.02,0.15$ and 0.35 , then it shows in order, the weak, mild and strong predictive power in case of the construct indexes. According to table 2, it gets clear that the model has strong predictive power, as the values for predictive power in organizational structure, empowerment, knowledge management are $0.381,0.467$, and 0.455 that are greater than 0.35 .

General Model's GOF: this index shows the compromise between the quality of measurement model and structural model equaling to:

$$
\text { GOF }=\sqrt{\text { Communalities } \times \overline{\mathrm{R} 2}}=\sqrt{0.536 \times 0.852}=0.676
$$

The resulting values of this formula: $0.1,0.25,0.36$ are categorized at three weak, mild and strong levels. As it can be observed, using table 2 , the average communalities value and average $\mathrm{R}^{2}$ were calculated as 0.536 and 0.852 , so the general GOF of the model equals 0.676 , greater than 0.36 . Thus, one can claim that the research model GOF is very proper and at the level of "very strong". 
Now, considering the results of the standard coefficients model and the t-values model, we can investigate the hypotheses. The relations possessing t-values greater than 1.96, are significant at 95 percent confidence level. In table 5, the hypotheses and the results are investigated.

Table 5. Hypotheses and results

\begin{tabular}{|c|c|c|c|c|}
\hline $\begin{array}{l}\text { Hypot } \\
\text { heses }\end{array}$ & Hypotheses Routes & Sig & $\begin{array}{c}\text { Path } \\
\text { Coefficient }\end{array}$ & Result \\
\hline H1 & $\begin{array}{l}\text { There is significant relation between technology and knowledge } \\
\text { management. }\end{array}$ & 2.766 & -0.268 & Supported \\
\hline $\mathbf{H} 2$ & $\begin{array}{l}\text { There is significant relation between organizational culture and } \\
\text { knowledge management. }\end{array}$ & 2.815 & 0.346 & Supported \\
\hline H3 & $\begin{array}{l}\text { There is significant relation between emotional intelligence and } \\
\text { knowledge management. }\end{array}$ & 4.357 & 0.502 & Supported \\
\hline H4 & $\begin{array}{l}\text { There is significant relation between technology and organizational } \\
\text { structure. }\end{array}$ & 6.218 & 0.635 & Supported \\
\hline H5 & $\begin{array}{l}\text { There is significant relation between organizational culture and } \\
\text { organizational structure. }\end{array}$ & 3.221 & 0.348 & Supported \\
\hline H6 & $\begin{array}{l}\text { There is significant relation between organizational structure and } \\
\text { knowledge management. }\end{array}$ & 1.179 & 0.106 & Rejected \\
\hline H7 & There is significant relation between technology and empowerment. & 2.992 & 0.226 & Supported \\
\hline H8 & $\begin{array}{l}\text { There is significant relation between organizational culture and } \\
\text { empowerment. }\end{array}$ & 4.632 & 0.411 & Supported \\
\hline H9 & $\begin{array}{l}\text { There is significant relation between emotional intelligence and } \\
\text { empowerment. }\end{array}$ & 0.815 & 0.087 & Rejected \\
\hline H10 & $\begin{array}{l}\text { There is significant relation between organizational structure and } \\
\text { empowerment. }\end{array}$ & 3.539 & 0.362 & Supported \\
\hline H11 & $\begin{array}{l}\text { There is significant relation between empowerment and knowledge } \\
\text { management. }\end{array}$ & 1.975 & 0.283 & Supported \\
\hline
\end{tabular}

Source: own study

As it is obvious in table 5, the t-values levels are all higher than 1.96 except for $\mathrm{H} 6$ and $\mathrm{H} 9$, which confirms the significance of those hypotheses' relations.

\section{Discussion and conclusion}

In the present study, the age range 33-37 has the highest frequency with 44.3 percent of the all respondents and the least frequency belonged to 53-57 years of old with 4.9 percent. 63.9 percent of the respondents were male and 36.1 percent were female. Also, the highest frequency belonged to the instructors of Islamic Azad University with $24.6 \%$ and the least frequency related to Red Crescent University. $18 \%$ of the instructors had 5-year teaching record as the highest frequency and $1.6 \%$ had 16-year teaching record as the least frequency.

According to the results, Hypothesis 1 showed that there is a negative and significant relation between technology and knowledge management which was incompatible with the study results of Jokar (2010), Azizi et al., (2010), Damghanian et al., (2013), Sobhani et al. (2013), Tseng (2008), Neels \& Johnson (2010), Meyer \& Marion (2013). We know that the role of technology is to help people share their knowledge through communal organizational networks; in such a way that, the knowledge be accessible for the optimal use. 
However, one should look elsewhere to find out why such a negative relation was observed between technology and knowledge management, despite the confirmation of a positive one in the previous studies. From one perspective, we can regard this inconsistency in two aspects: firstly, proper processes have not been thought and provided for enhancing the individual access to needed technologies, and secondly not preparing the people and their negative attitude toward technology and resisting the technological progresses can have other reasons. If we view the technological approaches from another perspective, we see that three various approaches have been proposed by the experts about technology, its dimensions and its relation with organizational variables as follows. First, the technological inertia approach which refers to this idea that technology is by itself an effective factor. This approach is not in line with the present study and the negative relations among the variables are the evidence. Second, we have the organizational inertia which means the impact of technology depends on other factors such as the managers' attitude and philosophy, information system designers' attitude and idea and organizational factors. Hence, we can ascribe the negative relation of technology and knowledge management to the interactive effect of organizational structure and empowerment variables as the resistant factors in the form of a unified model. Third, there is the situational approach which refers to the fact that the relationship and interaction pattern of the organization member and their situations are important in technology's effectiveness. Therefore, if proper training and recruiting processes, participation field, awarding and teamwork do not exist among the instructors, then the relation between technology and knowledge management would remain unchanged. In this regard, it is suggested that the universities revisit their strategies in case of investments, in order to increase and promote the technological infrastructures, creating good technological processes such as creating and maintaining the communicational networks, training and preparing people before using modern technologies, etc.

In addition to the physical facilities, the spirits and beliefs appropriate for the workplace should be provided, which in this case, the organizational culture is highly important, and if in this case, no strategies is thought, then the whole process is impeded. The study results of Gholtash et al., (2011), Ashna et al., (2013), Balthazard \& Cooke (2004), Allameh et al., (2011) and Mueller (2014), shows that the universities' efficiency depends on the official plan of knowledge management, but in order to gain the necessary effectiveness out of these plans, we have to coordinate it with the current organizational culture. The relation of organizational culture and knowledge management was claimed as significant in $\mathrm{H} 2$ which is compatible with these studies. According to this result, the organizational culture is appropriate with the knowledge flow needed for designing the knowledge management, and it can also obvious that the member have full cooperation and commitment toward knowledge management.

Consequently, it indicates that the universities have selected their own approach, in case of knowledge management innovations, appropriate to the organizational culture. Apart from these factors, in the knowledge management success, one should note staff's intellectual capacities and feelings. Since the most important and the most precious asset in any organization, is the human resources, the more it is paid attention to, the more the organizational successful is. The previous studies have regarded the emotional intelligence as one of the effective and significant issues in knowledge management (Hosseini-Sadr, 2013; Mohseninia, 2013; Mohammadi, 2013; Safaju, 2015). These results are compatible with the third hypothesis of the research and they have confirmed the significant relation between the emotional intelligence and knowledge management. However, this result is not supported in Nazem \& Lajevardi (2011) research. Considering the results of the present study and its compatibility with most of the previous ones, it can be seen that the instructors' possession of emotional intelligence leads to the knowledge development in universities. It is suggested that psychological workshops in case of types of intelligences, communicational skills, motivation, etc. be held, the issues which are important factors in perception and communication of feelings and empowerments.

Woodward who believed in the classical management strategy (the best structure) emphasized that the effectiveness of an organizational performance depends on the proper structure for it, where in this case, technology is the key factor for determining the organizational structure. In other words, the technology type 
determines the best organizational structure for its effectiveness. This relation is investigated and confirmed in H4. The study results of Mostafaee,(2009); Azizi et al., (2013), Noruzi \& Navvabi, (2014), Dibrell \& Miller (2002), Chen (2007), and Chatzoglou et al., (2011) are in line with those of the present study. The results show that the technological activities processes paves the way for the organizational structure improvement and the technology type justifies the best organizational structure with high performance. The important issue here is that the levels and units available in the various organizations are effective in such relation. Hence, as the university instructors are professional and expert people and these kinds of organizations need modern technologies with flexible structure, then the universities should seek adhocracy and professional specialization. Also, the universities should pay attention to the general concept of technology which involves all three areas of hardware, software and minds. In other words, selecting technology should be based on certain needs and circumstances and it should change with the environmental changes.

Of the many important managers' tasks, one is to optimally adapt the organizational culture with the culture that is brought into the organization, with the imported technology. This relation forms H6 which showed that there is a significant relation between organizational culture and organizational structure. In their studies, Kordnaeij et al., (2009), Hariri \& Jafari (2012), Safari-Aboksari (2012) and Ahlin \& Bergstrom (2010) maintain that the relation between organizational culture and structure can facilitate getting to the objectives which indicates that reinforcing the organizational culture in universities can reinforce the organizational structure, in such a way that one can use organizational culture instead of official controls and in fact, the individuals themselves can contribute to control and conduct.

In case of investigating the relation between organizational structure and knowledge management as an interactive factor in the relation of technology and organizational culture with knowledge management, the organizational structure could not clarify the knowledge management available in universities and this led to the rejection of H6. The results of previous studies such as Naghipour et al., (2008), Karbassi-Yazdi (2011), Monavvarian et al., (2011) and Chen et al., (2010), were not compatible with the present study results. However, in most studies done on the relation of these two variables, the dimensions of organizational structure are considered and more analyses indicate the positive and negative relations of these dimensions with knowledge management which can be due to inconsistency of organizational structure as a unit. Also, in previous studies where the relations of organizational structure and organizational culture with knowledge management were discussed, the organizational culture was regarded as more effective factor in implementing knowledge management, so the difference can be regarding organizational structure as the mediator and lowering its effect under the impacts of organizational culture. Furthermore, considering the presence of instructors at universities and their belief in expertise, self-control, and flexibility in processes and decision-makings, one can infer that they seek to undermine the bureaucratic structures and barriers so that they could create communicational flows in universities through which they are able to access the needed information and knowledge as soon as possible. In this way, they could improve the knowledge management process status and also they can make it possible to gain access to information and knowledge of groups outside the university. It is suggested that the useful indexes and factors effective on knowledge management such as self-management, self-control, decentralization, participation, etc. be kept and factors such as interpersonal conflicts, keeping one's knowledge to oneself without sharing it, traditional structures, etc. which are undesired and ineffective be changed or modified. Also, it is proposed that the ones who respect knowledge management, be appointed in high spiritual and material positions.

In successful implementation of knowledge management of university instructors, the attention should be more on the knowledge-based technology rather the conventional productive one. In this regard, the ones who are directly in touch with the modern technology can contribute to the establishment of the knowledge management in the organization. $\mathrm{H} 7$ showed that there is a significant relation between technology and empowerment in universities which is compatible with the study results of Kamalian et al., (2013), Ebadi (2016) and Shirazi (2012). These results maintain that the use of technology can increase the knowledge and capacities of the 
organizational members in order to have easier, more accurate and inexperience communication while lowering the human error in information process network of the organization. Hence, it can be concluded that technology can demonstrate the human force empowerment changes in universities. Hence, the universities can take advantage of human force empowerments by designing proper plans and having correct strategies for using modern technologies. The results of the previous studies showed that the empowered workplace is influenced by a proper organizational culture which can lead to the staff's creativity, innovation and empowerment, by creating a communal environment full of human relationships.

Here, the results of the research was determined as significant in $\mathrm{H} 8$ on the relation between organizational culture and empowerment which is compatible with the results of the previous studies (Tavanee-Shahroodi \& Mahram 2010; Gholifar et al., 2011; Nassiri et al., 2012; Shaemi-Barzoki et al., 2013, Pearson, 2000; Dimitriades \& Maroudas). Now, we can say that since the instructors' empowerment needs strong and comprehensive culture in universities, the current status of organizational culture is good. Also, the results show that the educational systems of the universities are not managed in a centralized mode, and the instructors participate in the decisions and they can have important role in their empowerment. The proper organizational structure can also act as a mediator and a bridge between the organizational culture and empowerment, consolidating the bases for creativity, innovation and consequently the chain of organizational culture and empowerment. Also, it seems that the university environment has become a communal one where everyone cooperates with others and positive factors such as creativity, risk-taking, communication patterns, etc. -which are the environmental factors in the form of organizational culture on the way to reach the empowerment- have lowered the negative conflicts and contrasts. Considering the human force empowerment done through organizational culture in this study, it is suggested that the creative and critical thinking be indoctrinated in the universities as a culture and value, and the individuals and groups be encouraged to have cooperative behavior with one another.

Of the other effective issues in empowering the human force, many can be found in studies done by Babalhavaeji \& Aghakishizadeh (2010), and Abedi et al., (2011). They maintain that paying attention to emotional intelligence, especially the instructors' emotional intelligence and developing it is very important which is not compatible with previous studies and the hypothesis is rejected. The reason why the present study is not compatible with the previous studies can be analyzed in this way, that the emotional intelligence is formed generally in two dimensions of self-adjustment and self-adaptation. The self-adjustment dimension refers to the personal issues, so the lack of relation between the emotional intelligence and empowerment can be found in the individuals with less feeling and emotional intelligence. The other dimension deals with the self-adaptation or the interpersonal matters which is referred to as the social dimension of the emotional intelligence, as well. Hence, the other reason can be the inability or unwillingness of the instructors in interpersonal function. In other words, the second dimension of the emotional intelligence depends to the controlling ability of the emotions in one's self and others, so that the collective intelligence could be enhanced in order to empower oneself and the others. Thus, this dimension means that the individuals' unawareness or unwillingness can be another reason. Also, the professional skills can act as catalyzer in increasing the capacities of the individuals with emotional intelligence; hence, lacking professional skills can act as a reducer in the relation between these variables.

According to an approach, the empowerment is the process of giving an opportunity and authority to participate in the independent organizational decision-makings which needs a psychological transfer. Based on such approach, the duty of universities in empowering the human resources, is to create a structure in which the independence and flexibility are insisted. The H10 investigated this relation and led to the significant relation between these two variables which is compatible with the findings of Zabihi et al., (2012), Samadi-miarkolaee et al., (2015), Farahani et al., (2014), Miri et al., (2011), and Vazifehdoost et al., (2012). These results say that the organizational structure has a very important effect on the university staff empowerment process and besides the environmental factors and individual factors, one can gain the best status of empowerment by concentrating on that factor. The present study maintains the mentioned issue and says that the current structure in the 
universities have the necessary situation and grounds for creating, implementing and promoting the instructors' empowerment project, and this structure has direct impacts on instructors' empowerment implementation. On this basis, the universities have proper empowerment structure and there is good environment for empowerment process.

Finally, in $\mathrm{H} 11$ the relation between empowerment and knowledge management was investigated as a bridge among technology, organizational culture, and emotional intelligence which showed that there is significant relation between empowerment and knowledge management in universities. The study results of Rastadmehr et al., (2014), Hislop (2003), Shahnawaz (2006), O'Neill \& Adya (2007) and Young \& Allan (2013) are compatible with the results of the present study. These results show that the capacity and the role of human factor is very important and unique in knowledge management. Hence, enhancing the instructors' empowerment can promote their capabilities in knowledge management, remarkably. The more the instructors have higher capabilities, the more the capacity for creating knowledge in university would develop. The instructors, possessing more valuable knowledge, skill, experience, and expertise, can share them with others and in a way they increase the knowledge creation and application in the organization, as the knowledge is created in people's minds and the intelligent people can have rich knowledge resources, and since they have great analysis power and insight, they can contribute the knowledge management better.

\section{REFERENCES}

Abdi, F. (2010). Investigating the relation of two groups of organizational factors (structure and culture) and knowledge management in Imam Ali officers' academy. Military Management Journal, 10(39), 109-130.

Abdolali, S. (2010). Investigating the relationship between the organizational factors (structure, culture, technology) and knowledge management strategy in oil development and engineering company. MA Thesis, Payam-e-Noor University, Varamin Branch.

Abedi, S., Zare, H., Saeedipour, B., \& Soltani, A. (2011). The relation of managers' emotional intelligence and human resources' empowerment in payam-e-noor university. Educational Sciences Journal, 4(15), 107-127.

Ahlin, M., \& Bergstrom, L. (2010). Internal inconsistencies-cultural and structural conflicts. A case study of reforms within management control. Bachelor thesis in Business Economics, University of Gothenburg School of Business, Economics and law, Accounting and Management Control, Spring semester 2010.

Allameh, M., Zamani, M., \& Davoodi, S.M.R. (2011). The relationship between organizational culture and knowledge management (A case study: Isfahan university). Procedia Computer Science, 3, 1224-1236.

Alvani, S.M., Nategh, T., \& Farahi, M.M. (2007). The role of social capital in organizational knowledge management development. Journal of Iranian Management Sciences, 2(5), 35-70.

Ashna, M., Asgari, N., Moradi-Saleh, A., \& Ghafouri, D. (2013). The role of organizational culture in facilitating the knowledge management actions. Journal of Information Technology Management, 5(4), 1-22.

Assadi, S. (2013). Investigating the effect of organizational structure on knowledge management in power distribution company of western tehran. MA Thesis, Islamic Azad University, Central Tehran Branch.

Azizi, B., Mehrabi-Koushki, A., \& Jalali-Farahani, M. (2013). investigating the relation of information technology and organizational structure in youth and sports ministry of Iran. Sports Management Journal, 5(3), 161-174.

Azizi, Sh., Assadnezhad, M., Zare-Mirakabad, A., \& Hosseini, S.S. (2010). Investigating and comparing the knowledge management among the state and private organizations. Information Technology Management Journal, 2(4), 99-116

Babalhavaeji, F., \& Aghakishizadeh, V. (2010). The relation of emotional intelligence and empowerment of librarians: The case study of university libraries of Tabriz county. Knowledge Studies Journal (Library, Media and Information Technology Sciences), 3(10), 13-24.

Baghban, M. Hallaj-Dehghani, A., \& Moghian, D. (2012). Investigating information technology and organizational structure of islamic azad university, Bueen Zahra branch. Educational Management Research Journal, 3(4), 15-28.

Balthazard, P.A., \& Cooke, R.A. (2004). Organizational culture and knowledge management success: Assessing the behavior-performance continuum, Proceedings of the $37^{\text {th }}$ Hawaii International Conference on System Sciences. 
Bayat, Z. (2013). Investigating the effect of emotional, cultural and spiritual intelligence of managers on staff's empowerment in sina insurance company. MA Thesis. Payam-e-Noor University, Tehran Central Branch.

Bhatt, G. (2001) .Knowledge management in organizations: Examining the interaction between technologies, techniques and people. Journal of Knowledge Management, 5(1), 68-75.

Chatzoglou, P., Diamantidis, A., Vraimaki, E., Vranakis, S., \& Kourtidis, D. (2011). Aligning IT, strategic orientation and organizational structure. Business Process Management Journal, 17(4), 663-687.

Chen, Ch. (2007). Information technology, organizational structure, and new product development- The mediating effect of cross-functional team interaction. IEEE Transactions On Engineering Management, 54(4), 687-698.

Chen, Ch., Huang, J.W., \& Hsiao, Y. Ch. (2010). Knowledge management and innovativeness, The role of organizational climate and structure. International Journal of Manpower, 31(8), 848-870.

Damghanian, H., Zarei, A., \& Rouzban, F. (2013). Investigating the effect of information technology on knowledge management in national Iranian drilling company, Mediator: empowerment. Information Technology Management Journal, 5(4), 85-102.

Dibrell, C.C., \& Miller, T.R. (2002). Organization design: The continuing influence of information technology. Management Decision, 40(6), 620-627.

Dimitriades, Z. S. \& Maroudas, Th. (2007). Internal service climate and psychological empowerment among public employees. Transforming Government: People, Process and Policy, 1(4), 377-400.

Ebadi, S. (2016). Investigating the role and effect of information technology on professional empowerment of the staff of technical \& vocational training centers of Sistan and Baluchestan province. The $5^{\text {th }}$ National Seminar and $4^{\text {th }}$ International Seminar of Skill-Learning and Employment.

Farahani, A., Keshavarz, L., \& Ferdosi, M. (2014). Designing psychological empowerment model based on the relation of organizational structure and novel organizational culture in youth and sports ministry of Iran. Novel Approaches in Sports Management Journal, 2(7), 87-97.

Gholifar, E., Hajjari, S.Y., Hosseini, S.M., \& Rezaee, A. (2011). Confirmatory factor analysis of necessary items for empowering the faculty members of agriculture universities of Iran. Research and Planning in Higher Education Journal, 17(6), 37-58.

Gholtash, A., Salehi, M., Javdani, M., \& Sina, H. (2011). The relation of organizational culture and organizational learning with knowledge management of faculty members of islamic azad university. New Thoughts in Educational Sciences Journal, 7(1), 69-85.

Hardy, C., \& Leiba O.Sh. (1998). The power behind empowerment: Implication for research and practice. Human Relations, 51(4), 451-483.

Hariri, N., \& Jafari, M. (2012). The relation of organizational culture and organizational structure in the national library of Iran. National Library and Information Organization Studies Journal, 23(2), 122-138.

Hassanzadeh, M. (2009). Investigating the infrastructure factors of knowledge management in islamic republic of Iran. Bimonthly Journal of Shahed University, 16(35), 11-27.

Hislop, D. (2003) .Linking human resource management and knowledge management via commitment: A review and research agenda. Employee Relations, 25(2), 182-202.

Hosseini-Sadr, E., \& Abasaltian, A. (2013). Investigating the effect of emotional intelligence dimensions on individual inclination toward transferring knowledge in Iranian police organization. Journal Management System, 8(33), 31-53.

Jafari, M. Abolghasem-Gorji, H. Salehi, M., \& Rastegari-Mehr, B. (2011). The relation of the structural and cultural factors of an organization with knowledge management strategy in public healthcare and training centers of Tehran university of medical sciences. Health Management Journal, 14(45), 87 -94.

Jeibing, W., Bin, G., \& Yong Jiang, S. (2013). Customer knowledge management and IT-enabled business model innovation: A conceptual framework and a cose study from China. European Management Journal, 31(4), $359-372$.

Jokar, S. (2010), Investigating the relation between knowledge management and information technology among the managers of Shiraz university of medical sciences in year 2010. MA Thesis, Payam-e-Noor University, Shiraz Branch.

Kamalian, A., Salarzehi, H., \& Oliaee; Kh. (2013). The role of information technology in empowering the employees of technical \& vocational training organization. Academic Electronic Learning Journal, 4(2), 39-48.

Karbassi-Yazdi, M. (2011). Investigating the effect of organizational atmosphere and organizational structure on knowledge management in knowledge-based organization. MA Thesis. Allameh Tabatabaee University.

Kordnaeij, A., Bakhshizadeh, A., \& Fathollahi, M. (2015). Investigating the effect of psychological empowerment of the staff on structural empowerment. Organizational Behavior Studies Journal, 4(3), 97-119. 
Kordnaeij, A., Moghimi, S.M., Ghanati, S., \& Yazdani, H. (2009). Investigating the relation of organizational structure elements and entrepreneurial culture in university of Tehran. Governmental Management Journal, 1(3), 119-134.

Kruger, C.J., \& Johnson, R.D. (2010). Information management as an enabler of knowledge management maturity: A South African perspective. International Journal of Information Management, 30(1), 57-67.

Meyer, M.H., \& Marion, T.J. (2013). Preserving the integrity of knowledge and information in R\&D. Business Horizons, 56(1), 51-61.

Miri, A., Rangriz, H., \& Sabzikaran, E. (2011). The relationship between organizational structure and employees̉ empowerment in national Iranian oil products distribution company. Kuwait Chapter of Arabian Journal of Business and Management Review, 1(1), 51-68.

Mohammadi, S. (2013). Investigating the relation of emotional intelligence and knowledge management of the employees of export development bank of Iran. MA Thesis, Islamic Azad University, Central Tehran Branch.

Mohseninia, N. (2013). Investigating the effect of emotional intelligence of the employees on knowledge management of ferdosi credential and commercial institutes in Tehran province. MA Thesis, Islamic Azad University, Central Tehran Branch.

Monavvarian, A., Kheirandish, M., Asgari, N. (2011). Developing the organizational structure dimensions proportionate to the knowledge management approach. Information Technology Management Journal, 3(7), 133-150.

Mostafaee, H. (2009). The relation of it and organizational structure of chief offices of physical education of Iran. MA Thesis, University of Gilan.

Mueller, J. (2014). A specific knowledge culture: Culture antecedents for knowledge sharing between project teams. European Management Journal, 32(2), 190-202.

Naghipour, M., Azad, F., Dargahi, H., Ghazi-Mirsaeed, S.J., Hassanzadeh, M., \& Khansari, J. (2008). Investigating the organizational culture and organizational structure statuses in case of applying the knowledge management in central libraries of medical sciences universities of Iran. Paramedicine Faculty of Tehran University of Medical Sciences (Peyavard Salamat), 2(3), 42-49.

Nassiri, F., Ghanbari, S., Niknami, M., \& Akhundi, M. (2012). The relation between organizational culture and empowerment perception of high school managers of Hamedan city. Journal of Iranian Management Sciences, 3(1), 1-21. Nazem, F., \& Lajevardi, A. (2011). Investigating the relation of managers' emotional intelligence and knowledge management in oil industry. Educational Management Studies Journal, 3(2), 127-144.

Newman, B., \& Conrad, K. (2000). A framework for characterizing knowledge management methods, practices and technologies. Proc. of the Third Int. Conf. on Practical Aspects of Knowledge Management: Basel, Switzeland, 1-16.

Niaz-Azari, K., \& Amuee, F. (2007). The effective factors underlying knowledge management establishment in islamic azad universities of Mazandaran province. Journal of Research in Educational Planning (Knowledge and Research in Educational Sciences), 1(14), 93-106.

Noruzi, Y., \& Navvabi, T. (2014). Investigating the development of information technology and its relation with the organizational structure items and managerial functions: Case study of Shiraz university libraries. Academic Library and Communication Studies Journal, 48(1), 61-81.

O'Neill, B.S., \& Adya, M. (2007). Knowledge sharing and the psychological contract. Journal of Managerial Psychology, 22(4), 411-436.

Pillania, R. (2006). State of organizational culture for knowledge management in Indian industry. Global Business Review, 7(1), 119-135.

Rahmanseresht, H. Radmard, S.Gh., \& Galvani, M. (2011). The relation of organizational structure and knowledge management: A case study of deputy of pressed pieces production of Iran khodro company. Organizational Culture Management Journal, 9(23), 31-50.

Rastadmehr, B., Ashraf-Ganjuee, F., \& Sajjadi-Hazaveh, Seyyed-Hamid (2014). The effects of empowerment on knowledge management in sports federations staff. Sports Management Studies Journal, 6(25), 185-206.

Saadizadeh, N. (2014). Investigating the impact of empowering the personnel on establishment of knowledge management in central head quarter of mobile telecommunication company of Iran. MA Thesis, Islamic Azad University, Central Tehran Branch.

Safaju, A. (2015). The impact of emotional intelligence items on knowledge transfer (A case study of the national Iranian oil exploration organization. MA Thesis, Shahid Beheshti University.

Safari-Aboksari, M. (2012). Investigating the relation between organizational culture and organizational structure of youth and sports chief office of Mazandaran province. MA Thesis, Mazandaran University. 
Samadi-Miarkolaee, H., Aghajani, H., \& Samadi-Miarkolaee, H. (2015). The structural equations model of relation between the organizational structure and psychological empowerment of the staff (Case study: education office of Babolsar and bahnemir counties. Scientific Journal Management System, 6(1), 147-166.

Savery, L., \& Luks, A. (2000). The relationship between empowerment job satisfaction and reported strees levels: Some Australian evidence. Leadership \& Organization Development Journal, 22(3), 97-104.

Shaemi-Barzoki, A., Hatampour-Azarkharani, F., \& Radmehr, R. (2013). The relation of organizational culture and empowerment of university staff. Health System Research Magazine, 9 (6), 630- 639.

Shahnawaz, M. (2006). Antecedents of knowledge management practices supported by information technology. Thesis for Ph.D. Degree in Manugacturing Management and Engineering, The University of Toledo.

Shamshirkar, M. (2010). The relation of emotional intelligence and psychological empowerment of human resources (A case study of national copper industries company of Iran). MA Thesis, Shahid Beheshti University.

Shirazi, F. (2012). Information and communication technology and women empowerment in Iran. Telematics and Informatics, 29(1), 45-55.

Singler, T.H., \& Pearson, Ch. (2000). Creating an empowerment culture: Examining the relationship betweem organizational culture and perceptions of empowerment. Journal of Qulity Management, 5(1), 27-52.

Sobhani, Y., Honari, H., Shahlaee, J., \& Ahmadi, A. (2013). The relation of information technology and knowledge management in sport federations. Sports Management Journal, 17, 55-73.

Spreitzer, G.M. \& Mishra, A. (1997). Survivor responses to downsizing: The mitigating effects of trust and empowerment. Southern California Studies Center.

Spreitzer, G.M. (1995). Psychological empowerment in the workplace: dimensions, measurement, and validation. The Academy of Management Journal, 38(5), 1442-1465.

Stankosky, M., \& Baldanza, C. (2001). A system approach to engineering a knowledge management system in knowledge management. the catalyst for electronic government, edited by R.C. Barquin, A. Bennett and S.G. Remez. Vienna, Virginia, management concepts.

Storm, J., \& Wallace, M. (2003). Organizational change in a regional, local council. Australlasian Journal of Business \& Social Inquiry, 1(2), 1-14.

Tavanaee-Shahroodi, E., \& Mahram, B. (2010). Investigating the empowerment rate of elementary school teachers and its relation with school organizational culture items. Novel Educational Approaches Journal, 5(2), 23-40.

Tseng, Sh. (2008). The effects of information technology on knowledge management systems. Expert Systems with Applications, 3(1-2), 150-160.

Vazifedoust, H., Nasiri, M., \& Norouzi, A. (2012). Analyzing the relationship between organizational structure and employee empowerment in Eastern Azerbaijan. Interdisciplinary Journal of Research in Business, 2(6), 10-24.

Zabihi, M. Ebrahimipour, H., \& Arefinia, H. (2013). Investigating the relation between dimensions of organizational structure and psychological empowerment dimensions in Mashhad university of medical sciences staff. Nursing Management Journal, 2(1), 48-58.

Zavareghi, R. (2009). A glance on personal knowledge management: Approaches, instruments and skills. National Library and Information Organization Studies Journal, 20(2), 177-198.

Zheng, W., Yang, B., \& McLean, G.N. (2010). Linking organizational culture, structure, strategy, and organizational effectiveness: Mediating role of knowledge management. Journal of Business Research, 63, 763-771.

\title{
AUTHOR'S ADDRESS:
}

\author{
Shahram Shafiee \\ Department of Sport management \\ University of Guilan , Rasht, Iran \\ E-mail: Shafieeshahram@gmail.com
}

Received: 3 March 2019; Accepted: 20 February 2020 